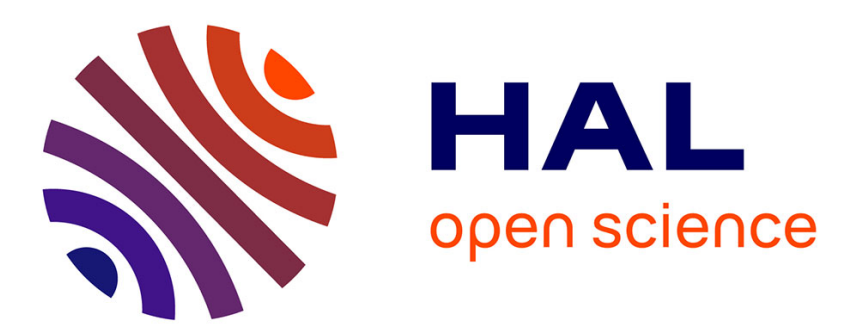

\title{
Metal/acid bifunctional catalysis and intimacy criterion for ethylcyclohexane hydroconversion: when proximity does not matter
}

Ester Gutierrez-Acebo, Charles Leroux, Céline Chizallet, Yves Schuurman, Christophe Bouchy

\section{To cite this version:}

Ester Gutierrez-Acebo, Charles Leroux, Céline Chizallet, Yves Schuurman, Christophe Bouchy. Metal/acid bifunctional catalysis and intimacy criterion for ethylcyclohexane hydroconversion: when proximity does not matter. ACS Catalysis, 2018, 8 (7), pp.6035 - 6046. 10.1021/acscatal.8b00633 . hal-01879819

\section{HAL Id: hal-01879819 \\ https: / hal-ifp.archives-ouvertes.fr/hal-01879819}

Submitted on 24 Sep 2018

HAL is a multi-disciplinary open access archive for the deposit and dissemination of scientific research documents, whether they are published or not. The documents may come from teaching and research institutions in France or abroad, or from public or private research centers.
L'archive ouverte pluridisciplinaire HAL, est destinée au dépôt et à la diffusion de documents scientifiques de niveau recherche, publiés ou non, émanant des établissements d'enseignement et de recherche français ou étrangers, des laboratoires publics ou privés. 


\section{Metal/acid bifunctional catalysis and intimacy}

\section{criterion for ethylcyclohexane hydroconversion:}

\section{when proximity does not matter}

Ester G. Acebo, ${ }^{1}$ Charles Leroux, ${ }^{1}$ Céline Chizallet, ${ }^{1}$ Yves Schuurman, ${ }^{2}$ Christophe Bouchy ${ }^{l} *$

${ }^{1}$ IFP Energies nouvelles, Rond-point de l'échangeur de Solaize, BP 3, Solaize, 69360, France

${ }^{2}$ IRCELYON, Institut de recherches sur la catalyse et l'environnement de Lyon, CNRS, UMR 5256, Université Lyon 1, 2 avenue Albert Einstein, F-69626 Villeurbanne, France

ABSTRACT. The apparent kinetics in metal/acid bifunctional catalysis is generally strongly affected by the metal to acid sites ratio, and their proximity. Although, these two key parameters are not systematically investigated in scientific literature. Such study is provided here for bifunctional catalysts using platinum as metallic function and EU-1 zeolite as acidic function. Two series of bifunctional catalysts with different metal to acid sites ratios and different metal to acid sites distances were prepared and tested in ethylcyclohexane hydroconversion. Increasing the metal to acid site ratio, the catalytic activity and isomerization selectivity increased until a plateau was reached, an observation which is in agreement with the classical bifunctional mechanism. At the same time, the intimacy criterion of Weisz was evaluated: strikingly, for a given metal to acid sites ratio, activities and selectivities are not affected by their distance (up to a micrometer scale). A dual function kinetic model was successfully applied in order to quantify 
the impact of the metal to acid sites ratio on the catalyst activity and isomerization properties. The application of this model showed that the metal to acid sites ratio needed to reach the catalytic activity plateau is higher than the ratio needed to reach the selectivity plateau. This was interpreted as a consequence of the lower kinetic constant rate for the naphthene ring opening reaction compared to the naphthene isomerization reaction.

KEYWORDS. Bifunctional catalyst, metal/acid balance, intimacy criterion, HEU-1 zeolite, platinum, ethylcyclohexane hydroconversion.

\section{INTRODUCTION}

Bifunctional catalysts containing both, a hydro/dehydrogenation and acid functions are used in several industrial refining processes, ${ }^{1,2}$ such as the hydroisomerization of $\mathrm{C}_{5}-\mathrm{C}_{6} n$-paraffins (to produce high-octane gasoline), ${ }^{3,4}$ and the production of diesel by hydrocracking of heavy oil. ${ }^{5,6}$ In the petrochemical field, ethylbenzene hydroisomerization is important for the paraxylene production. Paraxylene is a highly sought-after product used in the manufacture of the terephthalic acid, which is used for nylon production.

Bifunctional catalysts also play a key role in the production of alternative liquid fuels: produced either by hydroisomerization of hydrotreated vegetable oils ${ }^{7,8}$ or by hydroisomerization and hydrocracking of Fischer Tropsch waxes. ${ }^{9-11}$ They are also promising catalyst candidates for biomass conversion. ${ }^{12-14}$ Their complex behavior, due to the multi-step nature of the reactions, has been the object of deep investigations for decades. ${ }^{15-18}$ In spite of all these works, several key questions are still highly debated. ${ }^{15,18}$ 
A bifunctional catalyst is typically composed of a metallic compound dispersed over an acidic support. The metallic compound provides the hydro-dehydrogenation function and the support provides the isomerization and cracking functions. The hydro-dehydrogenation (HD/DHD) component can either be a noble metal (Pt, Pd) or a combination of non-noble metal-sulphides from Group VI A (Mo, W) and at least one from Group VIII A (Co, Ni). The acidic component can be an amorphous oxide like silica-alumina, a zeolite or a mesoporous material. The proper choice of the HD/DHD and the acidic component is dictated by the targeted application. For example, zeolites of the FAU type ${ }^{19}$ (USY zeolites) are used in hydrocracking whereas zeolites of the mordenite (MOR zeolites) and EUO types (EU-1 zeolites) can be used for ethylbenzene hydroisomerization. ${ }^{20}$

In the present work, we focus on EU-1 zeolite. The choice of EU-1 is firstly motivated by the fact that this zeolite is industrially used for the xylene and ethylbenzene isomerization processes to form para-xylene. Besides, interesting results have been obtained with EU-1 compared to mordenite-based catalysts. ${ }^{21}$ During the process, some naphthenes are formed by hydrogenation of the aromatics compounds on the HD/DHD function. For instance, ethylcyclohexane can be formed by ethylbenzene hydrogenation.

The classical bifunctional mechanism for the case of ethylcyclohexane hydroconversion is depicted in Figure 1. A first dehydrogenation reaction is required in order to provide olefinic reactants for the acidic catalyzed reaction to happen. Once the ethylcyclohexane is dehydrogenated into olefin, it diffuses towards the Brønsted acid sites and is protonated to form carbocations. These carbocations can in turn be isomerized, hydrogenated to their corresponding naphthene counterparts, or opened as $\mathrm{C}_{8}$ paraffins that can be cracked. 
For a given $\mathrm{HD} / \mathrm{HDH}$ and acidic component, the bifunctional catalyst performances are driven by two factors: the balance between the metal and acid function activities (futher referred as metal/acid balance $)^{22}$ and the distance between metal and acid sites. ${ }^{17}$ The metallic to acidic sites ratio is a convenient way to experimentally describe the metal/acid balance. ${ }^{23}$ When the metal function activity is high enough compared to the acid function activity ("well-balanced" catalyst) a plateau, where the HD/DHD reactions are at quasi-equilibrium, is reached. At this point, activity and selectivity are both dependent on the acid function. On the other hand, metal and acid sites should be sufficiently close to insure that the diffusion of olefinic intermediates does not impede the kinetics. A long time ago, Weisz ${ }^{17}$ established the so called "intimacy criterion", suggesting that it exists a certain critical distance between metal and acid sites. Below such distance, the catalyst performance is not impacted by the diffusion of olefinic intermediates. A well-balanced catalyst that fulfills the intimacy criterion can also be defined as an ideal bifunctional catalyst according to Weitkamp's terminology. ${ }^{22}$ 
Hydro/dehydrogenation function

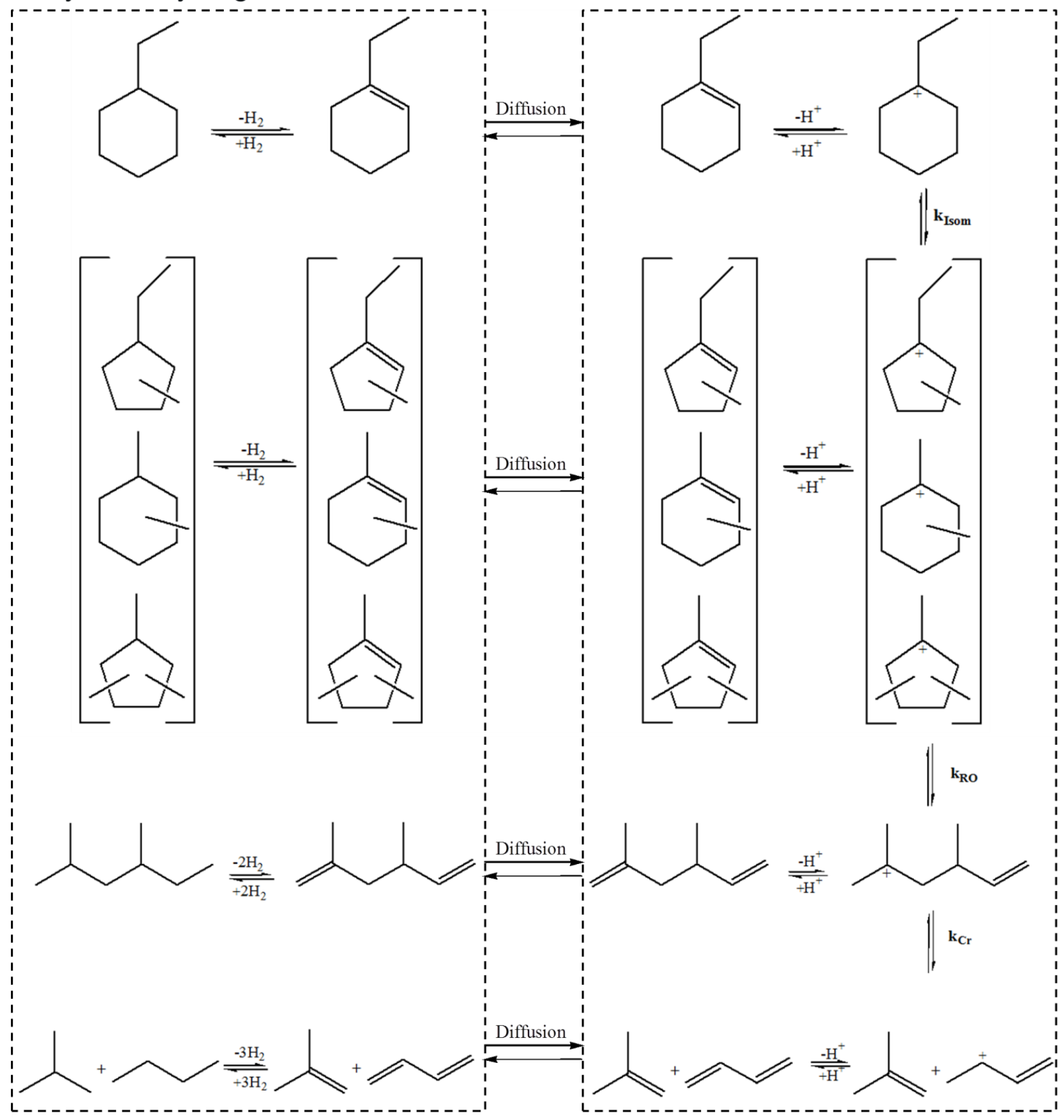

Figure 1. Simplified bifunctional mechanism for the hydroconversion of ethylcyclohexane. Alternative ring opening and cracking products are omitted for clarity.

For many years, several publications supporting this "intimacy criterion" have been published. This "intimacy criterion" has been often considered as "the closer the better". ${ }^{24-26}$ This "intimacy 
criterion" has been often considered as "the closer the better". Zečevićet al. ${ }^{18}$ have recently studied the hydroconversion of different paraffins with bifunctional catalysts, containing platinum and USY zeolite. In this work, they reported closer distances between the two functions as detrimental to the isomerization selectivity. This decrease in selectivity was attributed to the long residence time of the molecules inside the zeolite porosity., which will generate more cracking products. More recently, Samad et al., ${ }^{16}$ studied this phenomenon for n-heptane isomerization using a bifunctional catalyst (Pt dispersed over an acidic silica-alumina support). Their results pointed out in the same direction, showing lower activity at atomic distance between metal and acid sites than with larger ones, such as nano- and micro-meter distances. The same tendency was observed for the isomerization selectivity.

Regarding the balance between both functions, Batalha et al. ${ }^{25}$ reported that the latter has to be high enough to reach the plateau, where the rate limiting step of reaction takes place on the acidic function. Following that idea, Guisnet ${ }^{24}$ published later that this condition is necessary to obtain optimal catalytic performances.

Consequently, in order to achieve a general understanding, an unified view on the effects of the metal/acid balance and distance between sites is required. With this purpose, a systematic investigation of a combination of these two parameters has to be performed. Moreover, whereas their influence has been widely studied for paraffins hydroconversion, ${ }^{16,18,25,26}$ naphthenes hydroconversion has remained somehow in the background. To our knowledge, not many studies have been published. ${ }^{15}$ This reaction is of practical importance, since during ethylbenzene hydroisomerisation, naphthenes ring opening and cracking have been identified as the main side reactions impacting isomerization yields. ${ }^{20}$ 
In the present study, the influence of the distance and the balance between metal/acid functions for ethylcyclohexane $(\mathrm{ECH})$ hydroconversion over different platinum/EU-1 zeolite catalysts is investigated. The distance is tuned by impregnating platinum either on the zeolite, or on an alumina support. Although there are different ways to change the metal to acid sites ratio, we decided to change the amount of metal while keeping the number of acid sites constant. The metal to acid sites ratio could be also modified by tuning the zeolite $\mathrm{Si} / \mathrm{Al}$ molar ratio. However, this is far less reliable since changing the $\mathrm{Si} / \mathrm{Al}$ ratio while keeping all other properties (such as crystallinity, particle size, aluminum zoning, etc.) constant is not straightforward. For the trends investigated here, variations in these properties may be detrimental, as it was observed in the case of n-heptane hydroconversion catalyzed by Pt/FAU bifunctional catalysts. ${ }^{27}$

A reaction mechanism is proposed on the basis of a detailed analysis of the reaction products, and the trends observed are explained by a dual-function kinetic model.

\section{MATERIALS AND METHODS}

\subsection{Catalysts preparation}

Commercial zeolite EU-1 (CP742-1) was supplied by Zeolyst. The zeolite was first calcined at $520^{\circ} \mathrm{C}$ for $20 \mathrm{~h}$ to remove the organic template. To obtain the protonic form (HEU-1), it was then ion-exchanged with a solution of $\mathrm{NH}_{4} \mathrm{NO}_{3}\left(10 \mathrm{ml}\right.$ per gram of zeolite) at $85^{\circ} \mathrm{C}$ for $4 \mathrm{~h}$. under stirring. Afterwards, the solid was calcined under air flow of $1 \mathrm{NL} \mathrm{h}^{-1} \mathrm{~g}^{-1}$ at $150,250,350,450^{\circ} \mathrm{C}$ for $1 \mathrm{~h}$. at each temperature and a final plateau at $520^{\circ} \mathrm{C}$ for $20 \mathrm{~h}$. A heating rate of $5^{\circ} \mathrm{C} \min ^{-1}$ was used. The introduction of platinum on the zeolites (Pt/HEU-1) was performed by incipient wetness impregnation of $\left[\mathrm{Pt}\left(\mathrm{NH}_{3}\right) 4 \mathrm{Cl}_{2}\right] \cdot \mathrm{H}_{2} \mathrm{O}$ (99.5\%), supplied by Sigma-Aldrich. Three Pt contents were aimed for: $0.5,0.8$ and 1 wt.\%. The platinum introduction on alumina $\left(\mathrm{Pt} / \mathrm{Al}_{2} \mathrm{O}_{3}\right)$ 
was carried out by competitor impregnation of $\left[\mathrm{H}_{2} \mathrm{PtCl}_{6}\right] \cdot 6 \mathrm{H}_{2} \mathrm{O}(99.9 \%)$ supplied by Strem chemical, $\mathrm{HCl}$ being the competitor, and resulting in four Pt contents: $0.1,0.26,1.05$ and 2.3 wt.\%. The impregnated materials $\left(\mathrm{Pt} / \mathrm{HEU}-1\right.$ and $\left.\mathrm{Pt} / \mathrm{Al}_{2} \mathrm{O}_{3}\right)$ were dried overnight at $110^{\circ} \mathrm{C}$ and then calcined in an air flow of $1 \mathrm{NL} \mathrm{h}^{-1} \mathrm{~g}^{-1}$ at 150,250 and $350^{\circ} \mathrm{C}$ for $1 \mathrm{~h}$. at each temperature and finally at $520^{\circ} \mathrm{C}$ for $2 \mathrm{~h}$. A heating rate of $5^{\circ} \mathrm{C} \min ^{-1}$ was used. Ex situ reduction was performed to ensure a stable and consistent platinum state to all the catalytic tests and some characterization techniques. Reduction was performed at $480^{\circ} \mathrm{C}$ for $2 \mathrm{~h}$., using a heating rate of $5^{\circ} \mathrm{C} \mathrm{min}^{-1}$ and under a hydrogen flow of $20 \mathrm{NL} \mathrm{h}^{-1} \mathrm{~g}^{-1}$. Mechanical mixtures of $80 \%$ of $\mathrm{Al}_{2} \mathrm{O}_{3}$ (loaded or not with $\mathrm{Pt}$ ) and $20 \%$ of zeolite (loaded or not with Pt), with a pellet size below 60 $\mu \mathrm{m}$, were performed. The distance between metal and acid sites was considered as "microscale" when platinum is deposited on alumina $\left(\mathrm{Pt}-\mathrm{Al}_{2} \mathrm{O}_{3} / \mathrm{HEU}-1\right)$, and as "nanoscale" when platinum is deposited on the zeolite (Pt-HEU-1/ $/ \mathrm{Al}_{2} \mathrm{O}_{3}$ ) (See figure 2). The mechanical mixtures were pelletized with a hydraulic press, crushed and sieved to obtain a pellet size between 250 and 500 $\mu \mathrm{m}$. Table 1 summarizes all the catalysts employed in this study.

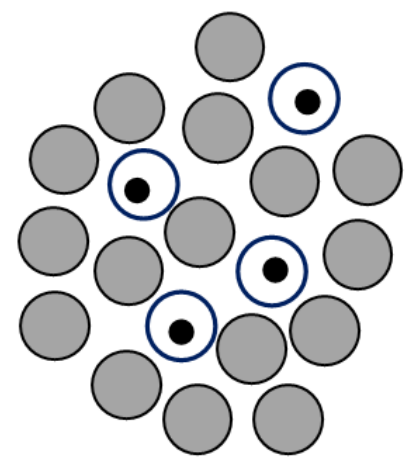

Nanoscale distance Pt-HEU-1/ $/ \mathrm{Al}_{2} \mathrm{O}_{3}$
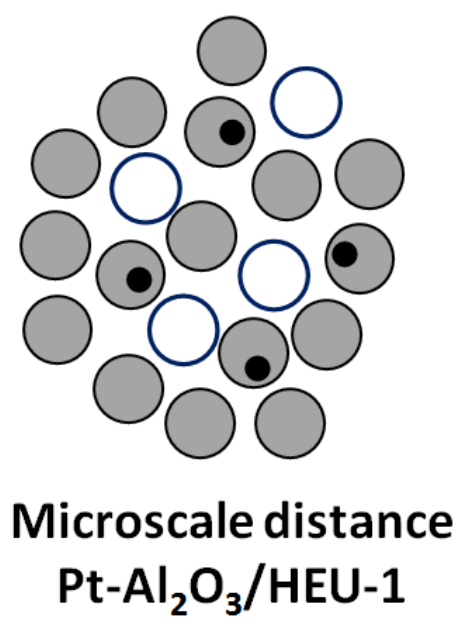

\section{Alumina}

Zeolite (EU-1)

- Platinum

Figure 2. Schemes of the two catalysts groups employed in this study showing different degrees of intimacy between metal and acid sites. 
Table 1. Bifunctional catalysts used in this study.

\begin{tabular}{|c|c|c|c|c|c|c|}
\hline \multirow[b]{2}{*}{ Pt location } & \multirow[b]{2}{*}{$\begin{array}{c}\text { metal/acid sites } \\
\text { distance }\end{array}$} & \multirow[b]{2}{*}{ Composition (wt \%) } & \multirow[b]{2}{*}{ Catalyst name } & $\mathrm{nA}$ & $\mathrm{nPt}_{\mathrm{s}}$ & \multirow[t]{2}{*}{$\mathrm{nPt}_{\mathrm{s}} / \mathrm{nA}$} \\
\hline & & & & $\left(\mu \mathrm{mol} \mathrm{Al} \mathrm{g}{ }^{-1}\right.$ cat $)$ & $\left(\mu \mathrm{mol} \mathrm{Pt} / \mathrm{g}^{-1} \mathrm{cat}\right)$ & \\
\hline \multirow{4}{*}{$\begin{array}{l}\text { Alumina } \\
\left(\mathrm{Pt}-\mathrm{Al}_{2} \mathrm{O}_{3}\right)\end{array}$} & \multirow{4}{*}{$\begin{array}{c}\text { Microscale } \\
\text { distance }\end{array}$} & $80 \% 0.10 \mathrm{wt} \% \mathrm{Pt}-\mathrm{Al}_{2} \mathrm{O}_{3}-20 \%$ HEU-1 & $0.1 \% \mathrm{Pt}-\mathrm{Al}_{2} \mathrm{O}_{3} / \mathrm{HEU}-1$ & 135 & 3.4 & 0.03 \\
\hline & & $80 \% 0.26 \mathrm{wt} \% \mathrm{Pt}-\mathrm{Al}_{2} \mathrm{O}_{3}-20 \%$ HEU-1 & $0.3 \% \mathrm{Pt}-\mathrm{Al}_{2} \mathrm{O}_{3} / \mathrm{HEU}-1$ & 129 & 9.1 & 0.07 \\
\hline & & $80 \% 1.05 \mathrm{wt} \% \mathrm{Pt}-\mathrm{Al}_{2} \mathrm{O}_{3}-20 \% \mathrm{HEU}-1$ & $1 \% \mathrm{Pt}-\mathrm{Al}_{2} \mathrm{O}_{3} / \mathrm{HEU}-1$ & 142 & 38.1 & 0.27 \\
\hline & & $80 \% 2.30 \mathrm{wt} \% \mathrm{Pt}-\mathrm{Al}_{2} \mathrm{O}_{3}-20 \% \mathrm{HEU}-1$ & $2.3 \% \mathrm{Pt}-\mathrm{Al}_{2} \mathrm{O}_{3} / \mathrm{HEU}-1$ & 142 & 68.7 & 0.48 \\
\hline \multirow{3}{*}{$\begin{array}{c}\text { Zeolite } \\
\text { (Pt/HEU-1) }\end{array}$} & \multirow{3}{*}{$\begin{array}{l}\text { Nanoscale } \\
\text { distance }\end{array}$} & $80 \% \mathrm{Al}_{2} \mathrm{O}_{3}-20 \% 0.51 \mathrm{wt} \% \mathrm{Pt} / \mathrm{HEU}-1$ & $0.5 \%$ Pt-HEU- $1 / \mathrm{Al}_{2} \mathrm{O}_{3}$ & 132 & 4.3 & 0.03 \\
\hline & & $80 \% \mathrm{Al}_{2} \mathrm{O}_{3}-20 \% 0.82 \mathrm{wt} \% \mathrm{Pt} / \mathrm{HEU}-1$ & $0.8 \% \mathrm{Pt}-\mathrm{HEU}-1 / \mathrm{Al}_{2} \mathrm{O}_{3}$ & 132 & 6.9 & 0.05 \\
\hline & & $80 \% \mathrm{Al}_{2} \mathrm{O}_{3}-20 \% 0.95 \mathrm{wt} \% \mathrm{Pt} / \mathrm{HEU}-1$ & $1 \%$ Pt-HEU- $1 / \mathrm{Al}_{2} \mathrm{O}_{3}$ & 129 & 8.1 & 0.06 \\
\hline
\end{tabular}

$\mathrm{n}_{\mathrm{A}}$ : micromoles of Brønsted acid sites per gram of catalyst

$\mathrm{n}_{\text {Pts: }}$ : micromoles of surface Pt per gram of catalyst

\subsection{Materials characterization}

Zeolites were characterized by X-ray fluorescence to determine the global $\mathrm{Si} / \mathrm{Al}$ molar ratio. ${ }^{27} \mathrm{Al}$ magic angle spinning nuclear magnetic resonance (MAS NMR) was employed to determine the percentage of framework and extra-framework aluminum. XRF analyses were performed with a Thermo scientific ARL Perform'X. NMR experiments were performed using a Bruker Ultrashield $400 \mathrm{MHz}$ spectrometer equipped with a $4 \mathrm{~mm} \mathrm{CP}$ MAS probe head at room temperature. The MAS rate was $12 \mathrm{kHz}$ for all experiments, the sequence used for $\mathrm{Al}$ is a $\mathrm{zg}$ sequence and a delay time of $0.5 \mathrm{~s}$. The number of Brønsted acid sites was calculated from these two techniques (number of $\mathrm{Al}^{\mathrm{IV}}$ equal to number of Brønsted sites). For this calculation, Na residual presence, measured by atomic absorption spectroscopy (AAS) has been considered. Quantification of the zeolite global acidity was also assessed by ammonia Temperature Programmed Desorption ( $\left.\mathrm{NH}_{3}-\mathrm{TPD}\right)$. $\mathrm{NH}_{3}-\mathrm{TPD}$ was performed on an Autochem II 2920 apparatus, equipped with a TCD detector, coupled with a Pfeiffer mass spectrometer. The samples were first pre-treated at $500^{\circ} \mathrm{C}$ under Helium $\left(50 \mathrm{~mL} \mathrm{~min}^{-1}, 2 \mathrm{~h}\right)$, before adsorption of $10 \% \mathrm{NH}_{3} / \mathrm{He}$ at $150^{\circ} \mathrm{C}$ during $30 \mathrm{~min} .\left(50 \mathrm{~mL} \mathrm{~min}^{-1}\right)$, followed by a purge under helium $\left(150^{\circ} \mathrm{C}\right.$, 
$60 \mathrm{~min}$., $\left.50 \mathrm{~mL} \mathrm{~min}{ }^{-1}\right)$. The TPD was performed under a flow of helium $\left(50 \mathrm{~mL} \mathrm{~min}{ }^{-1}\right)$ from $150^{\circ} \mathrm{C}$ to $600^{\circ} \mathrm{C}$, with a $10^{\circ} \mathrm{C} \min ^{-1}$ ramp.

Crystallinity was measured by X-ray diffraction (XRD) using a X'Pert Pro diffractometer from Philips Analytical, using a $\mathrm{Cu}$ Ka radiation $(\lambda=1.5406 \AA)$. Diffraction profiles were scanned using the step mode over a $2 \theta$ range of $5-40^{\circ}$, in steps of $0.02^{\circ}$ for six hours with a step time of 5 s. at each point. Nitrogen adsorption measurements were carried out at $-200^{\circ} \mathrm{C}$ on an automatic Micromeritics ASAP 2420 apparatus. Before adsorption, zeolite samples were degassed under vacuum at $500^{\circ} \mathrm{C}$ for $6 \mathrm{~h}$. The total porous volume $\left(\mathrm{V}_{\text {total }}\right)$ was calculated from the adsorbed volume of nitrogen at a relative pressure $\mathrm{P} / \mathrm{P}_{0}$ of 0.98 whereas the microporous volume $\left(\mathrm{V}_{\text {micro }}\right)$ was determined using the t-plot method. ${ }^{28}$ The mesoporous volume $\left(\mathrm{V}_{\text {meso }}\right)$ was obtained by the difference between $\mathrm{V}_{\text {total }}$ and $\mathrm{V}_{\text {micro. }}$.

Platinum dispersion on alumina was determined by hydrogen titration of chemisorbed oxygen $\left(\mathrm{H}_{2}-\mathrm{O}_{2}\right.$ titration $)$ in a Gira Xisorb apparatus with a thermal conductivity detector. The samples were first calcined under air at $530^{\circ} \mathrm{C}$ for $2 \mathrm{~h}$. at $5^{\circ} \mathrm{C} \min ^{-1}$, then cooled down to room temperature and purged with $\mathrm{He}$. The first reduction with $\mathrm{H}_{2}$ was done at $450^{\circ} \mathrm{C}$ for $2 \mathrm{~h}$. with a flow of $20 \mathrm{NmL} \mathrm{min}^{-1}$. After cooling down to room temperature and purging with $\mathrm{He}, 15$ pulses with pressures from 0.5 to $60 \mathrm{kPa}$ of oxygen were added until saturation occurred (oxygen titration). Another He purge was done before a second reduction with $\mathrm{H}_{2}$ at room temperature. Then 10 pulses with pressures from 0.5 to $60 \mathrm{kPa}$ of hydrogen were added until saturation (hydrogen titration). Platinum dispersion on zeolite was determined by scanning transmission electron microscopy (STEM) performed using a JEOL 2100 TEM microscope operated at $15 \mathrm{kV}$. The Pt particles average size was estimated using a shape factor for a cube with one non-exposed side $(\mathrm{F}=5)$ as recommended in literature for supported metal particles. ${ }^{29}$ IR spectroscopy of 
adsorbed $\mathrm{CO}$ measurements were performed with a Bruker Vertex 70 with the purpose to characterize the Pt electronic state. The sample was reduced before analysis at $480^{\circ} \mathrm{C}$ for $15 \mathrm{~min}$. under static hydrogen and $15 \mathrm{~min}$. for purging (this process was repeated three times). The CO chemisorption was carried out with pulses under vacuum from 5 mbar. to 1000 mbar. until saturation. The pressure in the chamber was then reduced and kept at 120 mbar. This method also allowed to calculate the Pt dispersion. The molar amount of $\mathrm{CO}$ adsorbed was considered as equal to the molar amount of exposed Pt on the surface.

\subsection{Catalytic test}

Ethylcyclohexane hydroconversion was performed between 230 and $330^{\circ} \mathrm{C}$ at a total pressure of 10 bar, using a steel fixed bed reactor. The reactor effluent was analyzed on-line with a gas chromatograph (GC) equipped with a 20 m. DB-1 capillary column from Agilent Technologies and a flame ionization detector (FID). 5 g. of catalyst were loaded in the reactor for each catalytic test. Before reaction, the catalyst was reduced under hydrogen $\left(20 \mathrm{NL} \mathrm{h}^{-1} \mathrm{~g}^{-1}\right)$ at $480^{\circ} \mathrm{C}$

for $2 \mathrm{~h}$. using a heating rate of $5^{\circ} \mathrm{C} \min ^{-1}$. The hydrogen to ethylcyclohexane molar ratio was 40 , and the weight hourly space velocity (WHSV) was set to $4 \mathrm{~g}$. of ethylcyclohexane per gram of catalyst per hour. The conversion was changed by increasing the temperature. For each temperature two GC analyses were performed in order to check the catalyst stability. Return points confirmed that catalyst deactivation was negligible during the test. The ECH conversion and product selectivities were calculated from the integration of peak areas coming from the chromatograph. It was assumed that the total peak area corresponded to the total amount of products. All the peak areas were corrected with a calculated response factor, specific for each family product depending on their number of carbon atoms and type of compounds. For instance, 
the naphthenic $\mathrm{C}_{8}$ isomers were lumped into their corresponding families, i.e. all the dimethylcyclohexane $(\mathrm{DMCH})$ isomers were lumped into the so-called DMCH family, the trimethylcyclopentane (TMCP) and ethylmethylcyclopentane (EMCP) ones into the TMCP and EMCP families, respectively (see supporting information, Table S1) and the propylcyclopentanes into the PCP family. The apparent kinetic constant for first-order ethylcyclohexane consumption per catalyst gram per unit of time was calculated at each temperature by using the integrated form of the rate equation. Selectivity towards a product or a family of products was calculated as the weight of the specific product or family of products divided by the total products weight. The turnover frequency (TOF, in $\mathrm{s}^{-1}$ ) per acid site was calculated according to Eq. $1 .^{30}$

$$
T \mathrm{OF}=\frac{\mathrm{F}_{0}(\mathrm{ECH})}{\text { Wcat }_{\mathrm{A}}} \ln \left(\frac{1}{1-\mathrm{X}}\right) \quad \text { Eq. } 1
$$

$\mathrm{F}_{0}(\mathrm{ECH})$ is the molar flow of ECH at the entrance of the reactor $\left(\mu \mathrm{mol} \mathrm{s}{ }^{-1}\right), \mathrm{W}_{\text {cat }}$ is the amount of catalyst $(\mathrm{g}), \mathrm{n}_{\mathrm{A}}$ is the amount of Brønsted acid sites per gram of catalyst $\left(\mu \mathrm{mol} \mathrm{g} \mathrm{g}^{-1}\right.$ ) and $\mathrm{X}$ is the ethylcyclohexane conversion.

\subsection{Thermodynamic and kinetic modeling}

Thermodynamic simulations were performed with SimSci Pro/II v 9.2 (Schneider Electric). The thermodynamic equation of state used was SRK (Soave-Redlick-Kwong). The compounds database was that from SimSCi. The equilibrium between the different compounds was evaluated with a Gibbs reactor (outlet pressure 10 bar, $\mathrm{T}$ between 230 and $330^{\circ} \mathrm{C}, 50$ iterations max, convergence tolerance -based on the relative change of Gibbs free energy between two iterations: $10^{-6}$, Fibonacci tolerance: 0.01$)$.

The kinetic modeling was based on the scheme depicted in figure 3 that represents the main reactions occurring for our system according to a bifunctional mechanism. 


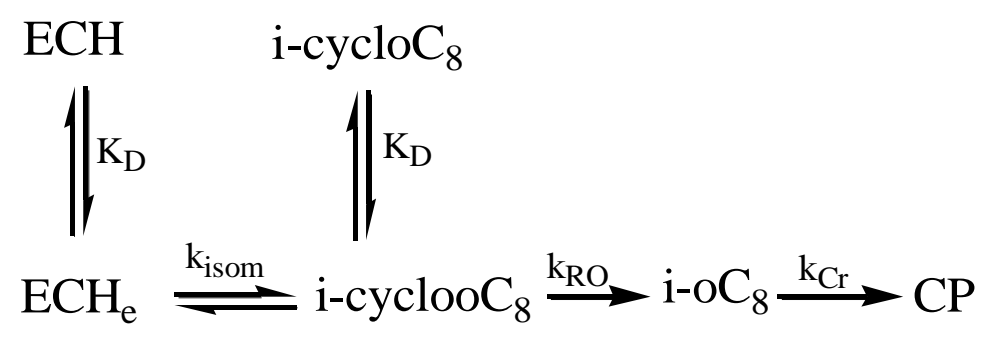

Figure 3. Representative scheme of the bifunctional mechanism for the main reactions appearing in the $\mathrm{ECH}$ hydroconversion. $\mathrm{K}_{\mathrm{D}}, \mathrm{k}_{\mathrm{isom}}, \mathrm{k}_{\mathrm{RO}}$ and $\mathrm{k}_{\mathrm{Cr}}$ are the apparent equilibrium $\left(\mathrm{K}_{\mathrm{D}}\right)$ and rate constants for dehydrogenation, isomerization, ring opening and cracking steps, respectively.

In order to describe this system, a dual-function kinetic model published recently by Mendes et al. $^{30}$ for the hydroisomerization of paraffins was applied to our results.

With this model it is possible to quantify the impact of the metal to acid sites ratio on the catalyst performance. Nevertheless, the proximity between the two functions is not taken into account into the model.

The two descriptors of the catalytic performances are the turnover frequency per Brønsted acid site (TOF in $\mathrm{s}^{-1}$ ) and the maximal yield of naphthenic isomers ( $\mathrm{Y}_{\mathrm{i} \text {-cycloc8,max, in wt.\%) }}$ representing the maximal yield (i-cyclo $\mathrm{C}_{8}$ isomers selectivity multiplied by the conversion) of $\mathrm{C}_{8}$ naphthenes isomers obtained during the reaction. Their expressions are given by Eq.2 and 3 .

$$
\begin{gathered}
\text { TOF }=\frac{\alpha}{1+\beta \cdot\left(\frac{n_{A}}{n_{P t_{S}}}\right)} \quad \text { Eq. } 2 \\
Y_{i-\text { Cycloc } 8, \max }=\frac{\gamma}{1+\varepsilon \cdot\left(\frac{n_{A}}{n_{P t_{S}}}\right)} \quad \text { Eq. } 3
\end{gathered}
$$

Where $\left(\frac{n_{A}}{n_{P t_{S}}}\right)$ is the catalyst amount of Brønsted acid sites per number of surface Pt.

These equations were derived based on the reaction scheme shown in Figure 3 for a plug-flow reactor and assuming first order isomerization and ring opening/cracking reactions. The 
$\mathrm{DH} / \mathrm{HDH}$ reaction rates were assumed to be a function of: the fractional vacancy and the total number of metal sites, as well as of the difference between paraffin partial pressure and the corresponding equilibrium pressure. Furthermore it was assumed that the fraction of occupied acid sites is low and unaffected by olefins partial pressures. Further details are provided in ref 28.

Four parameters describe the kinetic model. $\alpha$ corresponds to the intrinsic $\mathrm{TOF}_{\mathrm{Al}}$ of the zeolite, where $\mathrm{TOF}_{\mathrm{Al}}$ is the average turnover frequency per Brønsted site along the reactor. $\beta$ is a measurement of the $\mathrm{n}_{\mathrm{Pts}} / \mathrm{n}_{\mathrm{A}}$ ratio required to reach the intrinsic $\mathrm{TOF}_{\mathrm{Al}}$ of the zeolite. In the expression of the maximum yield $\mathrm{i}$-cycloC $8, \gamma$ reflects the highest value of $\mathrm{Y}_{\mathrm{i}-\mathrm{cycloc} 8 \text {,max }}$ that can be reached. and so the intrinsic zeolite selectivity towards hydroisomerization. $\varepsilon$ is a measurement of the $\mathrm{n}_{\mathrm{Pts}} / \mathrm{n}_{\mathrm{A}}$ ratio required to attain such value. In the model of Mendes et al. ${ }^{30} \varepsilon$ and $\beta$ are related to the kinetic constants of cracking and isomerization respectively, i.e. $\varepsilon / \beta$ equals $\mathrm{k}_{\mathrm{Cr}} / \mathrm{k}_{\text {isom. }}$. When a naphtene molecule like ethylcylcohexane is considered, ring opening is required before cracking can occur. Moreover, ring opening is a limiting step compared to the cracking (see. 3.2). Therefore in this case $\varepsilon / \beta$ equals $\mathrm{k}_{\mathrm{RO}} / \mathrm{k}_{\mathrm{isom}}$.

\section{RESULTS}

\subsection{Characterizations of the samples}

\subsubsection{Pt/HEU-1 samples}

Table 2 reports the main physical-chemical properties of the non-impregnated and impregnated zeolites. After zeolites impregnation, crystallinity remained constant, around 100\% (figure S1). The amount of sodium after ionic exchange was low, below $100 \mathrm{ppm}$. The microporous and

mesoporous volumes were in all cases around 0.13 and $0.21 \mathrm{~mL} \mathrm{~g}^{-1}$ respectively, meaning that the Pt deposition had no influence on these physical properties of the zeolite. Concerning the 
acidity, once again no effect was observed after Pt impregnation, as illustrated by the constant total amount of acid sites in both zeolites (based on the amount of $\mathrm{Al}^{\mathrm{IV}}$ ), of about $650 \mu \mathrm{mol} \mathrm{g}^{-1}$. The negligible impact of the platinum deposition on the acidity was also confirmed by ammonia temperature programmed desorption experiments. The initial calcined zeolite and the one loaded with the highest Pt content ( $1 \%$ Pt-HEU- $\left.1 / \mathrm{Al}_{2} \mathrm{O}_{3}\right)$, that one with the highest pore blockage effect expected, were characterized and compared revealing similar $\mathrm{NH}_{3}$ desorption profiles. Afterwards, the profiles were decomposed in order to quantify the amount of acid sites corresponding to the highest temperature peak. These results demonstrated a negligible decrease of the amount of acid sites (within the experimental error, of $\pm 10 \%$ ) for the impregnated zeolite sample $\left(678 \mu \mathrm{mol} \mathrm{g}^{-1}\right)$ compared to the initial one $\left(710 \mu \mathrm{mol} \mathrm{g}^{-1}\right)$. These values are in agreement with the acid site concentration calculated from Si/Al ratio and ${ }^{27} \mathrm{Al}$ NMR (Table 2). Thus, we can conclude that the platinum particles are located in such a way that they do not affect the access to the acid sites.

According to STEM characterization (figure 4), platinum was rather well dispersed over the zeolite and the average particle size was $1.2 \mathrm{~nm}$ corresponding to $82 \%$ dispersion. Similar dispersions were obtained (Table 2) regardless of the amount of impregnated Pt. In all samples, some larger particles were found representing less than $10 \%$ of the total particle population. 


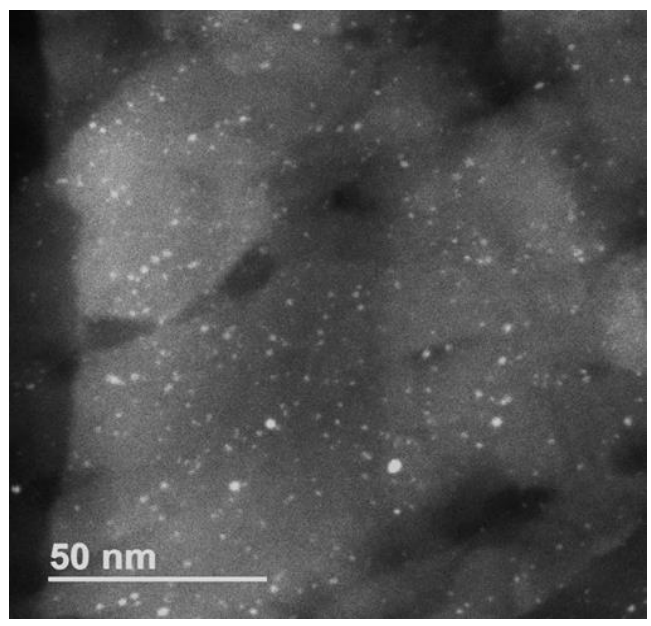

Figure 4. STEM image of 1\%Pt/HEU-1.

In the case of the $0.5 \% \mathrm{Pt} / \mathrm{HEU}-1$ sample, the $\mathrm{CO}$ adsorption monitored by FTIR revealed only a stretching band at $2090 \mathrm{~cm}^{-1}$, corresponding to $\mathrm{CO}$ adsorbed over Pt in a reduced state. ${ }^{31}$ In the samples with higher amounts of $\mathrm{Pt}$, especially in the case of $1 \% \mathrm{Pt} / \mathrm{HEU}-1$, some stretching bands at 2130-2110 $\mathrm{cm}^{-1}$ appeared (figure S2). They are attributed to $\mathrm{CO}$ in interaction with $\mathrm{Pt}^{+}$ species. ${ }^{31}$ A very good linear correlation was found between the peak area of the $\mathrm{Pt}^{0}-\mathrm{CO}$ species and the total number of Pt atoms (figure S3). This number has been calculated by taking into account the percentage of Pt present in each sample, measured by the XRF technique. This linear correlation sustained the fact that the dispersion was similar for all samples.

Table 2. Physical-chemical properties of the non-impregnated and impregnated zeolites.

\begin{tabular}{lllllllllll}
\hline Sample & $\begin{array}{l}\mathrm{S}_{\mathrm{BET}} \\
\left(\mathrm{m}^{2} \mathrm{~g}^{-1}\right)\end{array}$ & $\begin{array}{l}\mathrm{V}_{\text {micro }} \\
\left(\mathrm{mL} \mathrm{g}^{-1}\right)\end{array}$ & $\begin{array}{l}\mathrm{V}_{\text {meso }} \\
\left(\mathrm{mL} \mathrm{g}^{-1}\right)\end{array}$ & $\begin{array}{l}\mathrm{Pt} \\
(\mathrm{wt} \%)\end{array}$ & $\begin{array}{l}\mathrm{Na} \\
(\mathrm{wt} \%)\end{array}$ & $\begin{array}{l}\mathrm{Si} / \mathrm{Al} \\
\mathrm{Al}^{\mathrm{IV}} \\
(\%)\end{array}$ & $\begin{array}{l}\mathrm{n}_{\mathrm{A}} \\
\left(\mu \mathrm{mol} \mathrm{g}^{-1}\right)\end{array}$ & $\begin{array}{l}\mathrm{D}_{\mathrm{Pt}} \\
(\%)\end{array}$ & $\begin{array}{l}\mathrm{n}_{\text {PtsZ }} \\
\left(\mu \mathrm{molPt} \mathrm{g}^{-1}\right)\end{array}$ \\
\hline HEU-1 & 404 & 0.12 & 0.20 & - & 0.003 & 18.3 & 80 & 644 & - & - \\
$0.5 \%$ Pt/HEU-1 & 393 & 0.14 & 0.23 & 0.51 & 0.005 & 18.1 & 80 & 659 & 82 & 21 \\
$0.8 \%$ Pt/HEU-1 & 389 & 0.13 & 0.21 & 0.82 & 0.005 & 18.1 & 80 & 659 & 82 & 34 \\
$1 \%$ Pt/HEU-1 & 412 & 0.13 & 0.23 & 0.95 & 0.003 & 18.3 & 80 & 644 & 82 & 41 \\
\hline
\end{tabular}

$\mathrm{n}_{\mathrm{A}}$ : micromoles of acid sites per gram of zeolite

$\mathrm{n}_{\text {PtsZ: }}$ micromoles of surface Pt per gram of zeolite 
$\mathrm{D}_{\mathrm{Pt}}$ : dispersion

\subsection{2. $\mathrm{Pt} / \mathrm{Al}_{2} \mathrm{O}_{3}$ samples}

The $\mathrm{Pt} / \mathrm{Al}_{2} \mathrm{O}_{3}$ samples were analyzed after Pt deposition by nitrogen physisorption, $\mathrm{XRF}, \mathrm{H}_{2}-$ $\mathrm{O}_{2}$ titration and STEM. Nitrogen physisorption revealed that the surface area and mesoporous volume remained constant compared to the non-impregnated alumina (Table 3).

Table 3. Physical-chemical properties for the non-impregnated and impregnated alumina samples.

\begin{tabular}{llllll}
\hline Sample & $\begin{array}{l}\mathrm{S}_{\mathrm{BET}} \\
\left(\mathrm{m}^{2} \mathrm{~g}^{-1}\right)\end{array}$ & $\begin{array}{l}\mathrm{V}_{\text {meso }} \\
\left(\mathrm{mL} \mathrm{g}^{-1}\right)\end{array}$ & $\begin{array}{l}\mathrm{Pt} \\
(\mathrm{wt} \%)\end{array}$ & $\begin{array}{l}\mathrm{D}_{\mathrm{Pt}} \\
(\%)\end{array}$ & $\begin{array}{l}\mathrm{n}_{\text {PtsA }} \\
\left(\mu \mathrm{molPt} \mathrm{g}^{-1}\right)\end{array}$ \\
\hline Alumina & 190 & 0.53 & - & - & - \\
$0.1 \% \mathrm{Pt} / \mathrm{Al}_{2} \mathrm{O}_{3}$ & 194 & 0.52 & 0.1 & 81 & 4 \\
$0.3 \% \mathrm{Pt} / \mathrm{Al}_{2} \mathrm{O}_{3}$ & 200 & 0.55 & 0.26 & 85 & 11 \\
$1.1 \% \mathrm{Pt} / \mathrm{Al}_{2} \mathrm{O}_{3}$ & 200 & 0.55 & 1.05 & 89 & 48 \\
$2.3 \% \mathrm{Pt} / \mathrm{Al}_{2} \mathrm{O}_{3}$ & 203 & 0.52 & 2.3 & 73 & 86 \\
\hline
\end{tabular}

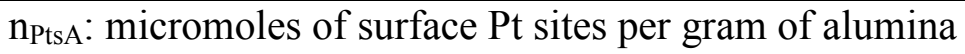

Pt dispersion was calculated by $\mathrm{H}_{2}-\mathrm{O}_{2}$ titration, a typical technique employed to determine platinum dispersion over alumina. ${ }^{32}$ Dispersions around $85 \%$ were found regardless of the amount of impregnated $\mathrm{Pt}$ (see Table 3). CO adsorption analysis revealed only the presence of $\mathrm{Pt}$ in the reduced state (figure S5).

\subsection{Catalytic tests}

\subsubsection{Catalytic behavior of $\mathrm{Pt}-\mathrm{HEU}-1 / \mathrm{Al}_{2} \mathrm{O}_{3}$ catalysts}


The catalytic test was carried out with the three different catalysts of this group, $0.5 \%, 0.8 \%$ and $1 \%$ Pt-HEU-1/ $/ \mathrm{Al}_{2} \mathrm{O}_{3}$. The evolution of the conversion was measured as a function of the temperature (figure 5 a).

According to the bifunctional mechanism first advanced by Weisz ${ }^{17}$ the higher the metal/acid ratio, the higher the conversion until reaching a plateau. This was well observed for this catalyst group: as the metal/acid balance increased the conversion increased (figure 5 a). However, a plateau was not reached in this metal content range. The apparent activation energy was around $119 \mathrm{~kJ} / \mathrm{mol}$ (figure S6) in the case of $1 \% \mathrm{Pt}-\mathrm{HEU}-1 / \mathrm{Al}_{2} \mathrm{O}_{3}$ and the maximal conversion reached was $93 \%$ at $330^{\circ} \mathrm{C}$.
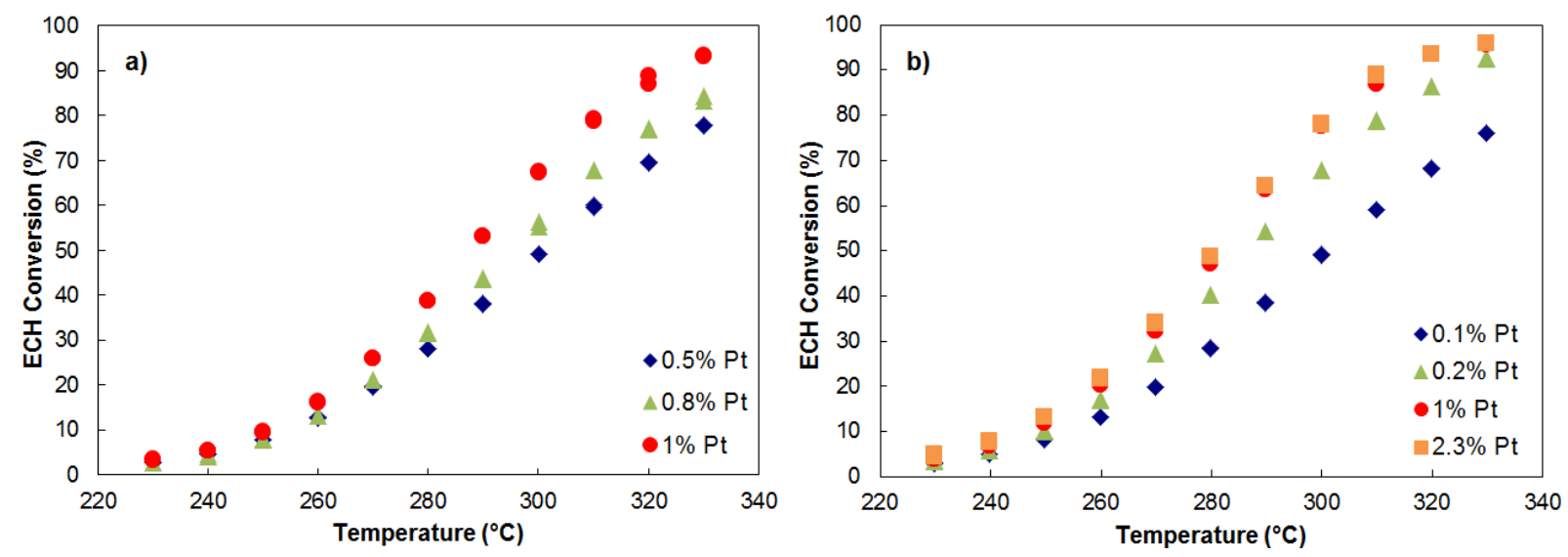

Figure 5. Evolution of the conversion versus temperature for a) the Pt-HEU-1/ $\mathrm{Al}_{2} \mathrm{O}_{3}$ catalysts; b) the Pt- $\mathrm{Al}_{2} \mathrm{O}_{3} / \mathrm{HEU}-1$ catalysts. 

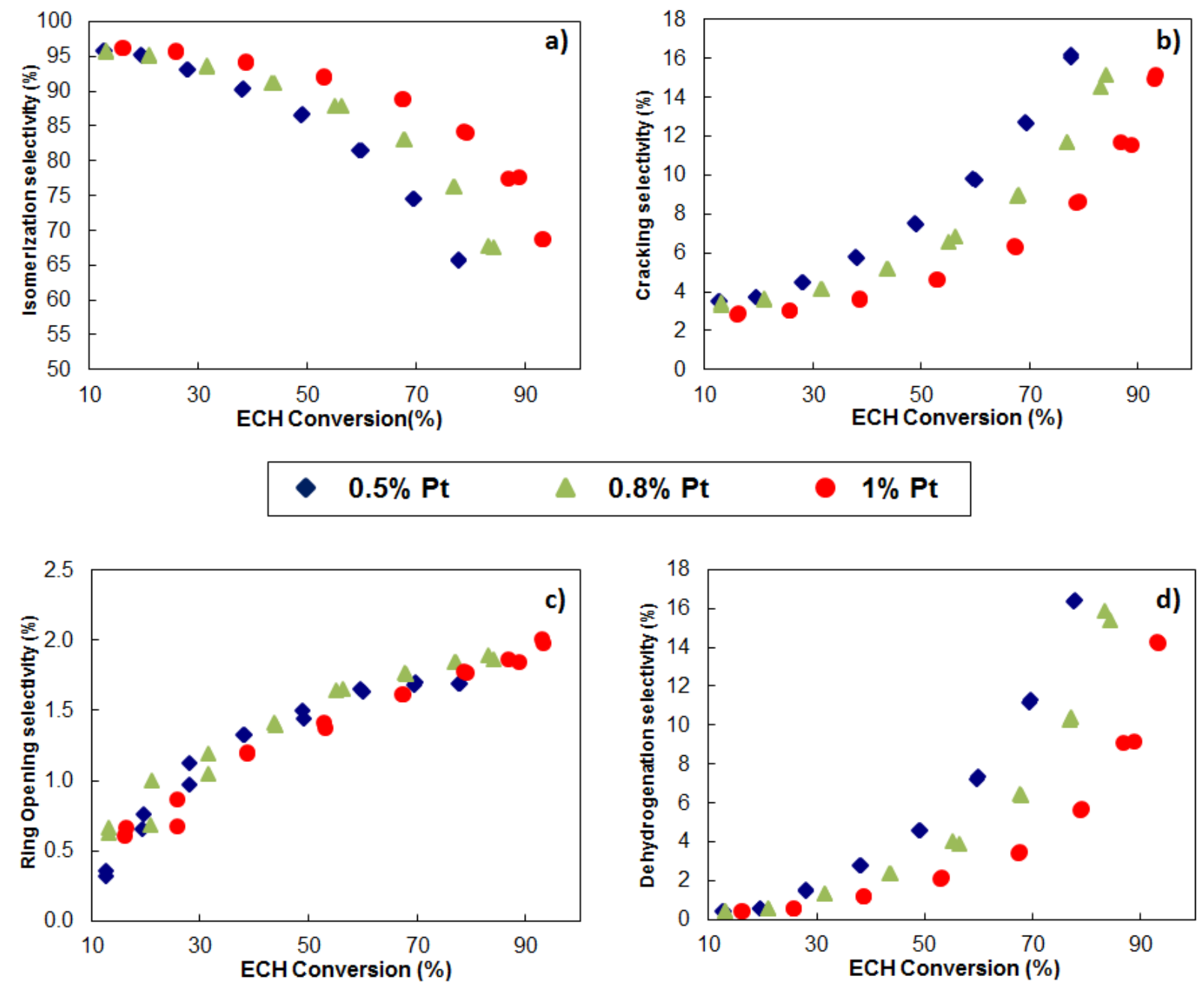

Figure 6. Evolution of the selectivity versus ECH conversion for the Pt-HEU-1/ $\mathrm{Al}_{2} \mathrm{O}_{3}$ catalysts; a) isomerization; b) cracking; c) ring opening; d) dehydrogenation.

In Figure 6 the evolution of the isomerization is depicted as a function of the ECH conversion. The same tendency as that observed for the conversion was found, i.e., the higher the metal/acid balance, the higher the isomerization selectivity. As a consequence, the selectivities towards the 
undesired side reactions, such as ring opening, cracking and dehydrogenation, decreased as long as the metal/acid balance increased (Figures $6 \mathrm{~b}, 6 \mathrm{c}$ and $6 \mathrm{~d}$ ).

Based on these curves, the primary products were easily identifiable as the isomerization ones, almost the only compounds appearing at low ECH conversions. Ring opening products were present only in very low amounts (lower than $2 \%$, figure 6c) whereas the cracking and dehydrogenation ones increased with the $\mathrm{ECH}$ conversion. This was consistent with the fact that naphthene ring opening is slow ${ }^{33}$ compared to naphthene isomerization and paraffin cracking (by beta scission). Thus, from these results, a first apparent reaction mechanism is proposed in Figure 7a. Product selectivities were also studied vs the contact time at a given temperature $\left(285^{\circ} \mathrm{C}\right)$, and basically the same conclusions were drawn.

For a deeper understanding of the isomerization reaction scheme, the various isomers were lumped according to their branching degree into different families (see section 2.3). The evolution of their mole fractions with temperature is reported in Figure $8 \mathrm{a}$ in the case of the $1 \%$ Pt-HEU-1/ $\mathrm{Al}_{2} \mathrm{O}_{3}$ catalyst. The thermodynamic equilibrium product distribution as a function of temperature was also calculated with PRO II (see section 2.4).

In the catalytic unit, this equilibrium was reached at higher temperatures (last point of figure 8a).

a) ECH $\Longrightarrow$ ISOMERIZATION products $\longrightarrow$ RING OPENING products $\longrightarrow$ CRACKING products

b)

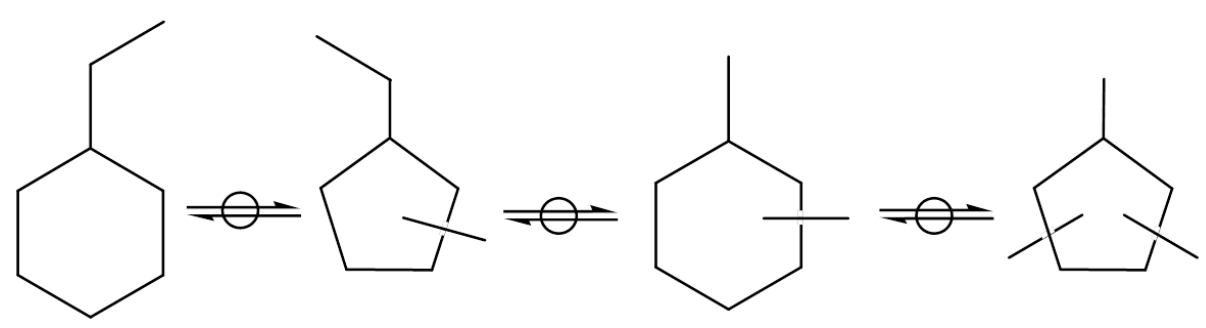


Figure 7.a) Apparent reaction mechanism for the hydroconversion of ECH and b) Apparent isomerization reaction scheme.
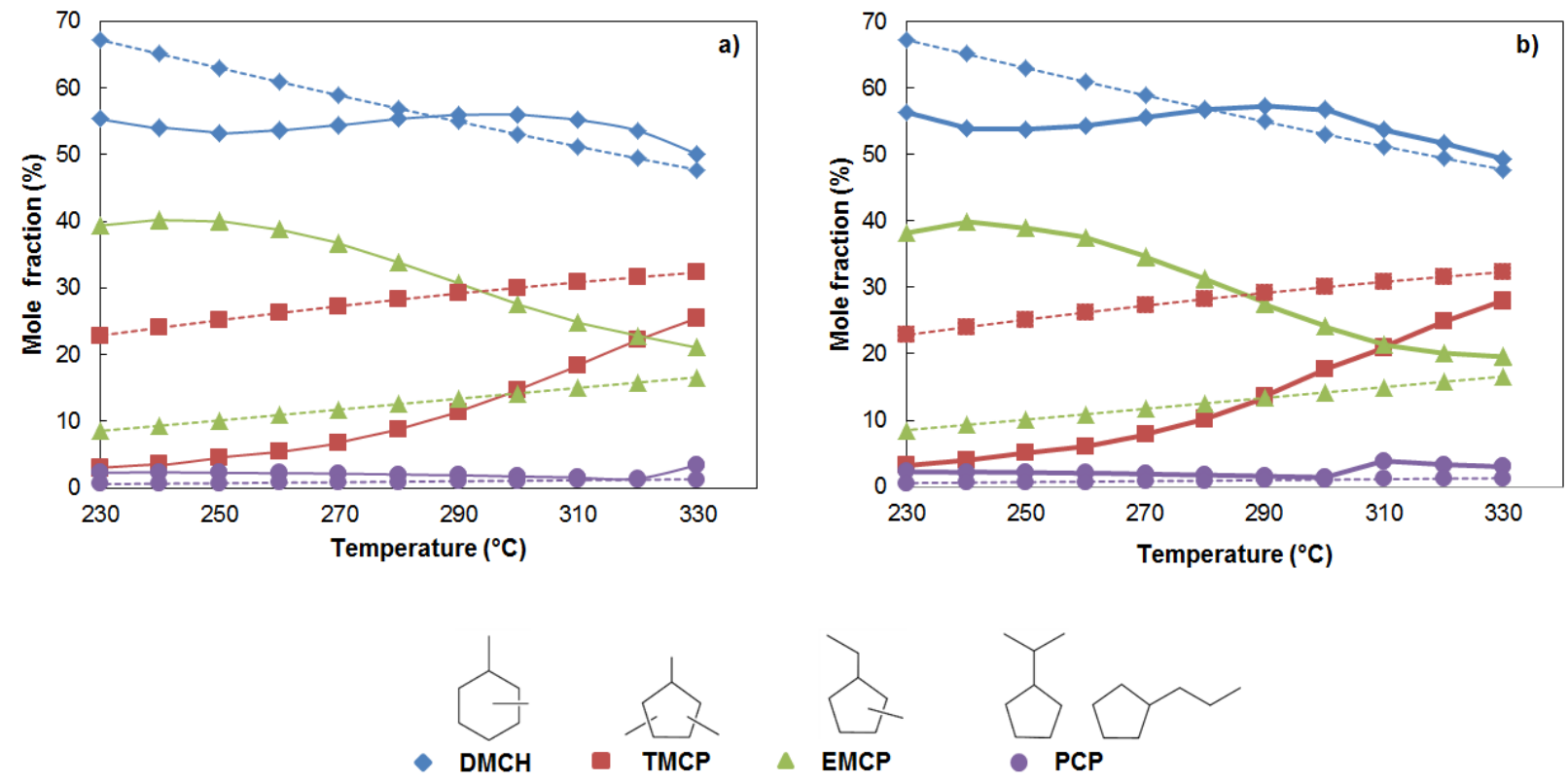

Figure 8. Evolution of the lumped isomers mole fraction versus temperature at thermodynamic equilibrium (dashed line, PRO II simulation) and observed experimentally (full line) for a) $1 \%$ Pt-HEU-1/ $\mathrm{Al}_{2} \mathrm{O}_{3}$ and b) $1 \%$ Pt- $\mathrm{Al}_{2} \mathrm{O}_{3} / \mathrm{HEU}-1$ catalysts.

$\mathrm{DMCH}$ and EMCP were the major reaction products at low $\mathrm{ECH}$ conversion, as inferred from Figure 8a. It can also be observed that the EMCP mole fraction at low conversion (i.e. low temperature) was much higher experimentally than at the thermodynamic equilibrium. Nonetheless, in the case of $\mathrm{DMCH}$, the experimental mole fraction was lower than the one at the thermodynamic equilibrium. This suggests that the primary isomerization products are EMCP and not $\mathrm{DMCH}$. The presence of $\mathrm{DMCH}$ at very low levels of conversion pointed out a fast isomerization from EMCP to $\mathrm{DMCH}$. It means, the ring expansion reaction (formation of 
$\mathrm{DMCH}$ from EMCP) seems to be faster that the ring contraction reaction (formation of EMCP from $\mathrm{ECH}$ ), otherwise $\mathrm{DMCH}$ would not appear as apparent primary products.

As the conversion increased, the EMCP mole fraction decreased as the TMCP mole fraction increased, while the DMCH mole fraction remained almost constant. This suggests that some DMCH is transformed into TMCP and concurrently EMCP into DMCH. Such fact can explain the constant $\mathrm{DMCH}$ mole fraction. On the other hand, the PCP concentration was negligible regardless of the conversion level, contrary to previous findings for zeolite $\mathrm{Y} .{ }^{15}$

Based on these experimental observations, an apparent reaction scheme for the $\mathrm{ECH}$ isomerization is depicted in Figure 7b.

The products molar distribution with carbon numbers other than 8 is depicted Figure 9. No larger paraffins than $C_{8}$ were observed. Typical products from hydrogenolysis, such as $C_{1}, C_{2}, C_{7}$ and $\mathrm{C}_{6}$, were found in low amounts. $\mathrm{C}_{3}-\mathrm{C}_{5}$ compounds are normally produced by the hydrocracking of $\mathrm{C}_{8}$ paraffins via a bifunctional mechanism (figure 1). These compounds were by far the most abundant ones, suggesting that the formation of cracked products mainly occurs via the bifunctional mechanism whereas the hydrogenolysis mechanism remains marginal. Besides, according to Weitkamp and Ernst, ${ }^{15}$ the higher amount of $\mathrm{C}_{5}$ with respect to $\mathrm{C}_{3}$ can be due to disproportionation followed by cracking reaction. According to these reactions, two $\mathrm{C}_{8}$ molecules dimerize and then crack into $\mathrm{C}_{5}+\mathrm{C}_{4}+\mathrm{C}_{6}$ or $2 \mathrm{C}_{5}+\mathrm{C}_{6}$ compounds. The existence of the disproportionation pathway was also sustained by the presence of $\mathrm{C}_{9}$ naphthenes. 


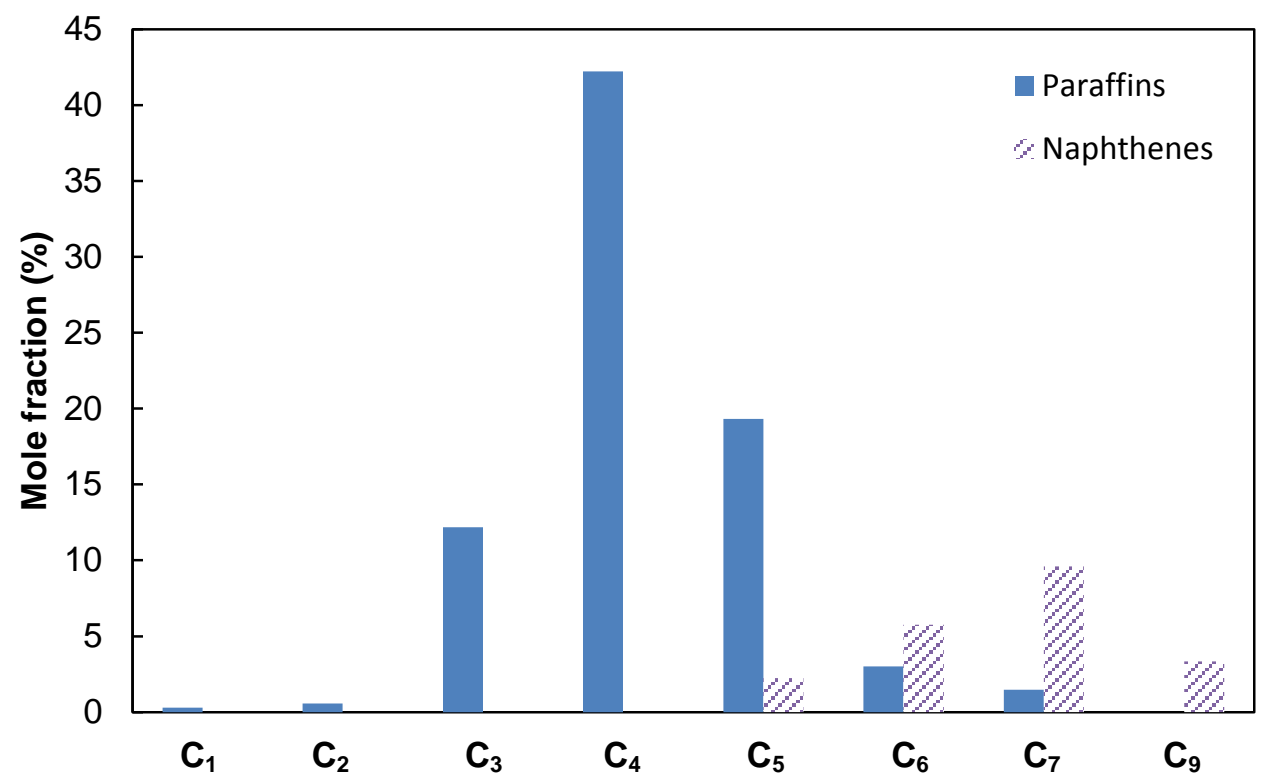

Figure 9. Molar distribution of products with carbon number other than eight at $300^{\circ} \mathrm{C}$ with the $1 \% \mathrm{Pt}-\mathrm{HEU}-1 / \mathrm{Al}_{2} \mathrm{O}_{3}$ catalyst. The yield of products with carbon number other than eight is equal to $4.2 \%$.

Ethylbenzene (EB) was the dehydrogenation product appearing first $\left(260^{\circ} \mathrm{C}\right)$ (figure $\mathrm{S} 7$ ), although its percentage remained low regardless of the temperature. The three xylenes: meta- (mXyl), para- (p-Xyl), and ortho-xylene (m-Xyl), appeared around $290^{\circ} \mathrm{C}$ and their concentration increased with higher temperatures (specially meta-xylene). This behavior was expected, since due to the endothermic character of the dehydrogenation, at higher temperatures the equilibrium is always shifted towards the formation of aromatics.

\subsubsection{Catalytic behavior of $\mathrm{Pt}-\mathrm{Al}_{2} \mathrm{O}_{3} / \mathrm{HEU}-1$ catalysts}

Four different catalysts with $0.1,0.2,1.0$ and $2.3 \mathrm{wt} . \% \mathrm{Pt}$ supported on alumina and mixed with the HEU-1 zeolite, were tested under standard conditions (section 2.3). The conversion was measured as a function of temperature and depicted in Figure 5 b. Again, the salient feature of 
the bifunctional mechanism was well observed: the higher the metal to acid sites ratio, the higher the conversion until reaching a plateau. This conversion plateau was reached when the curves related to the two catalysts containing 1 and $2.3 \%$ of Pt overlap as shown in Figure $5 \mathrm{~b}$. At this plateau, the hydro/dehydrogenation reactions (metal function) are at quasi-equilibrium and the limiting step of the reaction takes place on the acid sites. The $1 \% \mathrm{Pt}_{-} \mathrm{Al}_{2} \mathrm{O}_{3} / \mathrm{HEU}-1$ catalyst was considered as the reference system concerning this catalysts group, reaching a maximal ECH conversion of $96 \%$. The activation energy obtained with this catalyst was of $123 \mathrm{~kJ} / \mathrm{mol}$. These results revealed the importance of the metal/acid balance.
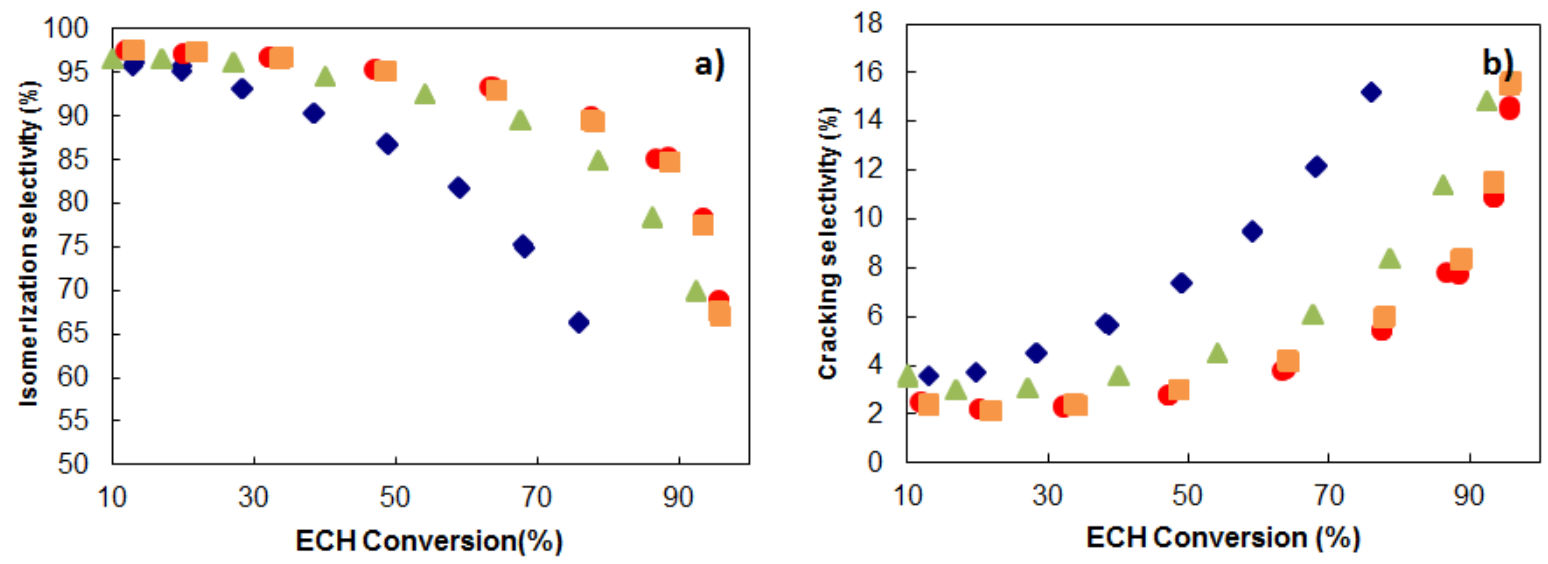

\begin{tabular}{|llll}
\hline $0.1 \% \mathrm{Pt}$ & $0.2 \% \mathrm{Pt}$ & $1 \% \mathrm{Pt}$ & $2.3 \% \mathrm{Pt}$ \\
\hline
\end{tabular}
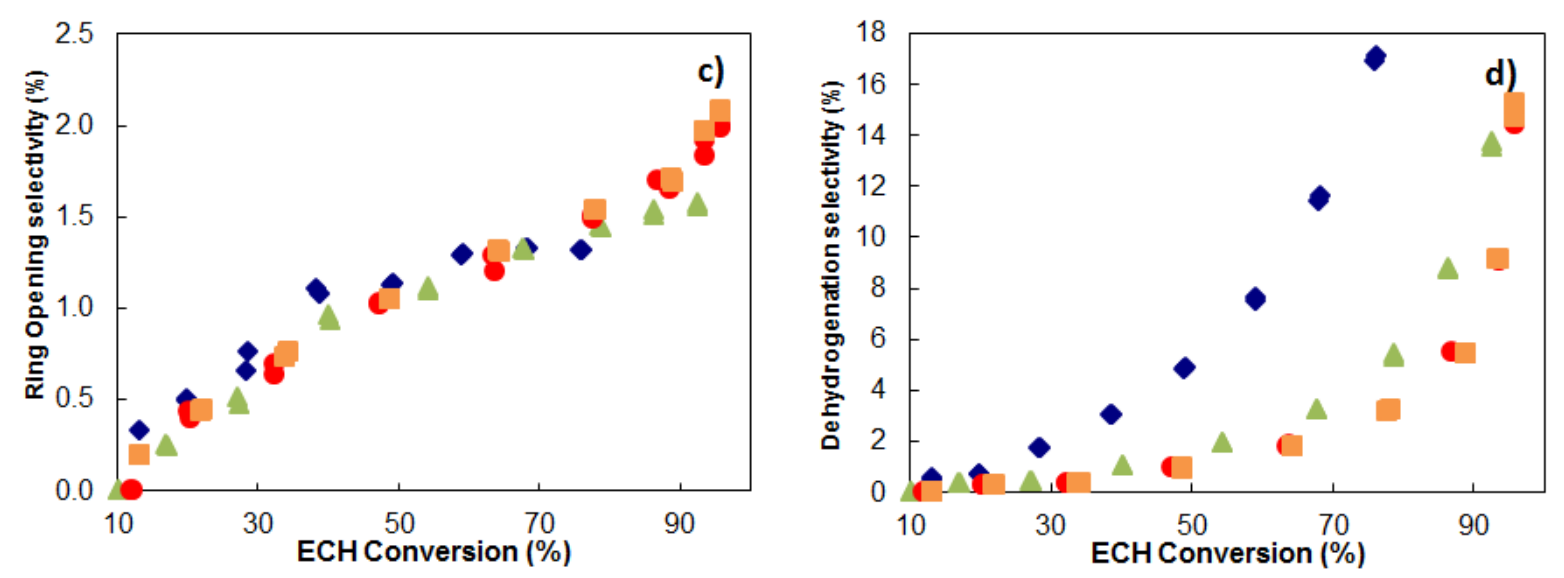
Figure 10. Evolution of the selectivity versus $\mathrm{ECH}$ conversion for the $\mathrm{Pt}-\mathrm{Al}_{2} \mathrm{O}_{3} / \mathrm{HEU}-1$ catalysts group; a) isomerization; b) cracking; c) ring opening; d) dehydrogenation.

Figure 10 shows that the selectivity also reached a plateau for the isomerization and the undesired side reactions. This selectivity plateau means that the quasi-equilibrium of the hydro/dehydrogenation reactions was reached for the products too. It is important to notice that the selectivity towards the undesired products (ring opening and cracking) remained really low. In particular, the selectivity for ring opening product was extremely low (below $2 \%$ ), regardless the ECH conversion.

These results were similar to those corresponding to the Pt-HEU- $1 / \mathrm{Al}_{2} \mathrm{O}_{3}$ group. Thus, the apparent reaction mechanism is the same as defined for the $\mathrm{Pt}-\mathrm{Al}_{2} \mathrm{O}_{3} / \mathrm{HEU}-1$ group, depicted in Figure 7a.

The isomers evolution was monitored experimentally (full line) over $1 \% \mathrm{Pt}-\mathrm{Al}_{2} \mathrm{O}_{3} / \mathrm{HEU}-1$ (Figure 8b). The data in Figure 8b is almost overlapping with those of Figure 8a. This implies that the evolution of the isomerization products with conversion was the same, regardless where the platinum was located. Therefore, the apparent isomerization reaction scheme is identical to that corresponding to the Pt-HEU-1/ $\mathrm{Al}_{2} \mathrm{O}_{3}$ series (figure $7 \mathrm{~b}$ ).

Concerning the evolution of cracking and dehydrogenation products, the results were almost the same as the ones corresponding to the $1 \% \mathrm{Pt}-\mathrm{HEU}-1 / \mathrm{Al}_{2} \mathrm{O}_{3}$ catalyst (figure $\mathrm{S} 9$ and $\mathrm{S} 10$ ).

\section{DISCUSSION}

\subsection{Ethylcyclohexane isomerization pathway over EU-1}

As for non-cyclic alkanes, two kinds of isomerization can be distinguished for naphthenes. ${ }^{2}$ On the one hand, type A isomerization does not change the naphthene branching degree. It 
corresponds for instance, to the ethylcyclohexane transformation into propylcyclopentanes. On the other hand, type B isomerization changes the naphthene branching degree. It corresponds for instance, to the ethylcyclohexane transformation into ethyl-methylcyclopentanes. Type A isomerization is generally reported to occur much faster than type B. ${ }^{2,34-36}$ However the zeolite topology has a significant impact on the relative rates of type A and type B isomerization. According to Weitkamp, ${ }^{30}$ mordenite favored type B isomerization compared to type A, as propylcyclopentane did not appeared as the primary product of ethylcyclohexane isomerization. By contrast, for other zeolites such as faujasite ${ }^{17}$ or ZSM-5, ${ }^{37}$ propylcyclopentane was indeed the primary isomerization product. The pore shape, or the structure dimension, can create some constraints related to the transition states or even to the reactant and the products. ${ }^{38}$ In the present study, for the EUO framework, the propylcyclopentanes do not appear as primary products. As for MOR, it is tempting to explain this result by an acceleration of type B isomerization compared to type A over EUO. However, such interpretation should be considered cautiously, since under our reaction conditions, the propylcyclopentanes formation is extremely disfavored from a thermodynamic point of view (figure 8). This point could be further investigated but is beyond the scope of this work.

\subsection{Impact of the metal to acid sites distance}

The impact of the metal/acid balance has been already highlighted in the previous sections. In order to evaluate the impact of the distance between both functions, the evolution of the turnover frequency per Brønsted acid site, TOF, and the maximal i-cycloC ${ }_{8}$ isomerization yield for both catalyst series versus the metal/acid balance is reported in Figure 11. $\mathrm{Pt}-\mathrm{Al}_{2} \mathrm{O}_{3} / \mathrm{HEU}-1$ corresponds to the catalysts with a "microscale distance" between the two functions whereas Pt- 
HEU- $1 / \mathrm{Al}_{2} \mathrm{O}_{3}$ corresponds to the catalyst with a "nanoscale distance" between the two functions. The metal/acid balance is represented by the molar ratio of surface platinum sites to Brønsted acid sites. For a given metal/acid balance, comparable turnover frequencies are obtained regardless of the platinum location (figure 11a). This suggests that the intimacy criterion is fulfilled even when the platinum and acid sites are at "microscale" distance. The same has been also observed before in Figure 5b.

Figure $11 \mathrm{~b}$ represents the evolution of the maximal $\mathrm{C}_{8}$ isomerization yield vs. the metal/acid balance. As it occurs for the TOF, the same trend is observed for the two catalyst series. For a given metal/acid balance, comparable maximal $\mathrm{i}-\mathrm{cyclo}_{8}$ isomerization yields are obtained regardless of the platinum location. Noticeably, the isomerization yield plateau seems to be reached at lower metal to acid ratio than the TOF. In this case study, the key parameter governing the activity and the selectivity of the bifunctional catalyst appears to be the metal/acid balance rather than the metal to acid sites distance.

Note that the desorption of the multibranched intermediates and products may be an issue under some operating conditions. The zeolite channels are indeed composed of $10 \mathrm{MR}$, even if side pockets are 12MR. Similar trends in terms of activity and selectivity are obtained for both catalysts series, while the diffusion path is likely not the same for all samples. This fact makes us confident that diffusion limitations in the microporosity are not occurring under our operating conditions. Note that they were carefully chosen to avoid the formation of aromatics. First to better study the intrinsic isomerization/cracking kinetics, but also to prevent the catalyst coking. The latter is known to occur when aromatics are produced in significant amounts.

\subsection{Impact of the metal to acid sites ratio}


To further quantify the impact of the metal to acid sites ratio on the catalytic performance, a dual-function kinetic model for the hydroisomerization of ethylcyclohexane was applied (section 2.4).

Figure 11a compares the evolution of the turnover frequency calculated by the kinetic model to the experimental data for both catalyst series, as a function of the metal/acid sites balance. The model describes the experimental behavior with good accuracy $\left(\mathrm{R}^{2}=0.85\right)$. Such model reveals the following fitted values for the parameters describing the kinetic model curve: $\alpha=0.03 \mathrm{~s}^{-1}$ and $\beta=0.02 . \alpha$ equals the intrinsic turnover frequency per Brønsted acid site whereas $\beta$ is a measure of the $\mathrm{n}_{\mathrm{Pts}} / \mathrm{n}_{\mathrm{A}}$ required to reach the plateau of the turnover frequency.
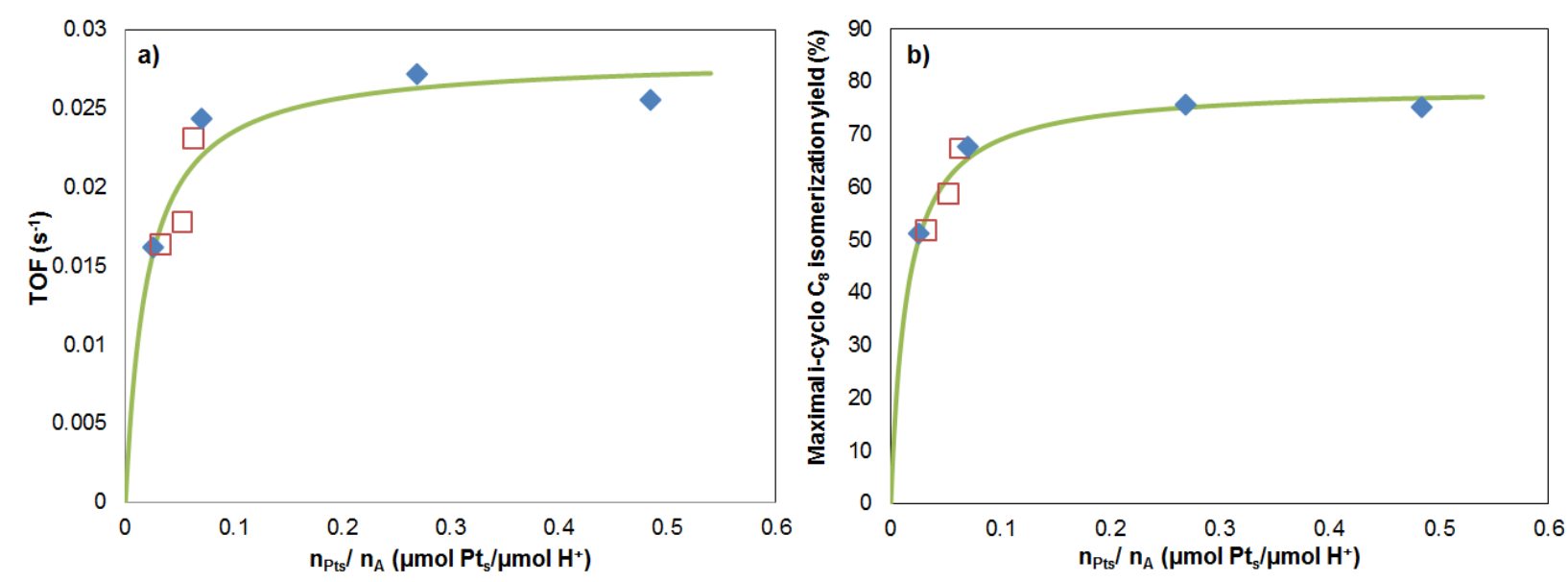

microscale distance $\square$ nanoscale distance $\longrightarrow$ Kinetic model

Figure 11. a) Experimental $\left(270^{\circ} \mathrm{C}\right)$ and model (according to the scheme first proposed in ${ }^{30}$ ) evolution of the a) TOF $\left(\mathrm{s}^{-1}\right)$ and b) maximal i-cyclo $\mathrm{C}_{8}$ isomerization yield, vs the metal/acid balance $\left(\mu \mathrm{mol} \mathrm{Pt} s / \mu \mathrm{mol} \mathrm{H} \mathrm{H}^{+}\right)$for both series of catalysts. 
The fitting of the maximal i-cyclo $\mathrm{C}_{8}$ isomerization yield against the metal/acid balance (figure $11 \mathrm{~b})$, also shows a very good agreement $\left(\mathrm{R}^{2}=0.94\right)$ with the experimental points. In this case, the values for the parameters describing the kinetic model are $\gamma=79.2 \%$ and $\varepsilon=0.015 . \gamma$ represents the highest $\mathrm{i}-\mathrm{cyclo}_{8}$ isomerization yield that can be reached and being intrinsic to the zeolite. $\varepsilon$ is a measure of $\mathrm{n}_{\mathrm{Pts}} / \mathrm{n}_{\mathrm{A}}$ required to reach the plateau for the maximal $\mathrm{i}-\mathrm{cycloC}_{8}$ isomerization yield.

The values obtained for $\beta$ and $\varepsilon$ are quite different. This reveals that the requirement in terms of metal to acid ratio, are not the same to reach the plateau for the turnover frequency and for the maximal $\mathrm{i}-$ cycloC $_{8}$ isomerization yield. The $\varepsilon / \beta$ ratio is around 0.75 . It means that the $\mathrm{n}_{P t s} / \mathrm{n}_{\mathrm{A}}$ ratio required to reach the plateau for the turnover frequency is higher compared to the one required to reach the plateau of maximal $\mathrm{i}-\mathrm{cycloC}_{8}$ isomerization yield. The $\varepsilon / \beta$ ratio is equal to the ratio of the apparent kinetic constants $\mathrm{k}_{\mathrm{RO}} / \mathrm{k}_{\mathrm{isom}}$. The value of the kinetic constant for isomerization is thus $4 / 3$ times higher than that for ring opening. It is in agreement with the sluggishness of the ring opening reaction compared to the isomerization one.

The dual function kinetic model was initially developed by Mendes $^{30}$ for n-paraffins hydroconversion and applied for n-hexadecane hydroconversion over FAU and BEA zeolites. In that case the $\varepsilon / \beta$ ratio is equal to the ratio of the apparent kinetic constant for isomerization and for cracking, $\mathrm{k}_{\mathrm{Cr}} / \mathrm{k}_{\text {isom, }}$, and was found equal to 2 . It means that the $\mathrm{n}_{\mathrm{Pts}} / \mathrm{n}_{\mathrm{A}}$ ratio required to reach the plateau for the turnover frequency is now lower compared to the one required to reach the plateau of maximal $\mathrm{iC}_{16}$ isomerization yield, i.e., the kinetic constant for isomerization is half the one of cracking. This is in agreement with the fact that type A beta-scission occurs faster than type A or type B isomerization. ${ }^{2}$ The different requirements in terms of metal to acid ratio 
necessary to reach the plateaus, are the consequence of the fundamental reactivity differences between hexadecane and ethylcyclohexane.

So, as a brief general conclusion, in the present study it is shown that the catalytic activity and selectivity depend strongly on the metal to acid sites ratio. Nevertheless, they are marginally affected by the distance between the active sites, and hence, by the diffusion path of the reaction intermediates. Despite such a simple model fits the data is somehow surprising, it reveals that indeed, the metal/acid balance is the key factor to rationalize the trends, from one sample to another. Note that we are not claiming that such a model is sufficient to precisely render the detailed feature of each catalyst one by one. In particular, it does not render the apparent mechanisms summarized in Figure 7. Additional investigations will be needed in the future to propose a detailed mechanism.

\section{CONCLUSIONS}

Bifunctional catalysts using platinum as metallic function and EU-1 zeolite as acidic function were prepared, characterized and evaluated for the ethylcyclohexane hydroconversion. Two groups of bifunctional catalysts with different metal/acid distances (nano-scale and micro-scale) were tested in this study. Within each group, the metal to acid sites ratio was varied.

We have shown that the catalytic activity and selectivity are strongly influenced by the metal to acid sites ratio. On the other hand, it was observed no influence of the distance between both functions, up to micrometer scale. This means that both groups of catalysts, either at nano- and micro- scale distances exhibit the same catalytic performance, provided that the metal to acid sites ratio is the same. Thus, the intimacy criterion is fulfilled in both cases. An ideal bifunctional 
catalyst is obtained when the metal to acid sites ratio is sufficiently high. In this case the rate limiting step of the reaction is taking place on the acidic function.

To quantify the impact on the metal to acid sites ratio on the catalytic performances (activity and isomerization selectivity), a dual function kinetic model was employed. The model describes the experimental catalytic performances with good accuracy. It shows that the catalyst activity plateau is reached at higher metal to acid sites ratio than the catalyst isomerization selectivity plateau. This is interpreted as a consequence of the lower value of the ring opening kinetic constant compared to the isomerization one.

\section{AUTHOR INFORMATION}

\section{Corresponding Author}

*Email: christophe.bouchy@ifpen.fr

\section{Funding Sources}

This work was supported by IFP Energies nouvelles.

\section{ASSOCIATED CONTENT}

\section{Supporting Information.}

Additional figures and tables, regarding catalytic and characterization results are given in the Supporting Information file. Additional information as noted in the text. This information is available free of charge via the Internet at http://pubs.acs.org.

\section{ACKNOWLEDGMENT}

We acknowledge Vincent Lecoq for his support with using PROII. 


\section{REFERENCES}

(1) Guisnet, M.; Gilson, J. P. in Zeolites for cleaner technologies; Catalytic science series 3, Imperial College Press: London 2002.

(2) Marcilly, C. in Acid-basic catalysis: Application to refining and petrochemistry; IFP publications, Editions Technip: Paris 2006.

(3) Kuchar, P. J.; Bricker, J. C.; Reno, M. E.; Haizmann, R. S. Paraffin isomerization innovations. Fuel Process Techno. 1993, 35,183-200.

(4) Primo, A.; Garcia, H. Zeolites as catalysts in oil refining. Chem. Soc. Rev. 2014, 43,75487561.

(5) Bertoncini, F.; Bonduelle-Skrzypcak, A.; Francis, J.; Guillon, E. Hydrocracking. in Catalysis by transition metal sulphides: from molecular theory to industrial applications, Editions Technip; Toulhoat, H., Raybaud, P. Eds.;, Paris 2013,609-677.

(6) Rana, M. S.; Sámano, V.; Ancheyta, J.; Diaz, J. A review of recent advances on process technologies for upgrading of heavy oils and residua. Fuel 2007, 86,1216-1231.

(7) Huber, G. W.; O’Connor, P.; Corma, A. Processing biomass in conventional oil refineries. Appl. Catal., A. 2007, 329,120-129.

(8) Sotelo-Boyás, R.; Liu, Y.; Minowa, T. Renewable Diesel Production from the Hydrotreating of Rapeseed Oil with Pt/Zeolite and $\mathrm{NiMo} / \mathrm{Al}_{2} \mathrm{O}_{3}$ Catalysts. Ind. Eng. Chem. Res. 2011, 50,2791-2799. 
(9) Böhringer, W.; Kotsiopoulos, A.; Boer, M. de; Knottenbelt, C.; Fletcher, J. Selective Fischer-Tropsch wax hydrocracking - opportunity for improvement of overall gas-to-liquids processing. Stud. Surf. Sci. Catal. 2007, 163,345-365.

(10) Davis, B. H.; Occelli, M. L. in Fischer-Tropsch synthesis, catalysts and catalysis, Studies in surface science and catalysis 163, Elsevier: Amsterdam, London 2007.

(11) Bouchy, C., Hastoy, G., Guillon, E., Martens, J. A. Fischer-Tropsch Waxes Upgrading via Hydrocracking and Selective Hydroisomerization. Oil Gas Sci. Technol.- Rev. IFP 2009, 64,91112.

(12) Huber, G. W.; Cortright, R. D.; Dumesic, J. A. Renewable alkanes by aqueous-phase reforming of biomass-derived oxygenates. Angew. Chem. Int. Ed. Engl. 2004, 43,1549-1551.

(13) Guan, G.; Kaewpanha, M.; Hao, X.; Abudula, A. Catalytic steam reforming of biomass tar. Renew. Sust. Energ. Rev. 2016, 58,450-461.

(14) Héroguel, F.; Rozmysłowicz, B.; Luterbacher, J. S. Improving Heterogeneous Catalyst Stability for Liquid-phase Biomass Conversion and Reforming. Chimia 2015, 69,582-591.

(15) Weitkamp, J.; Ernst. S. Comparison of the reactions of ethylcyclohexane and 2methylheptane on PdY zeolite. in Catalysis by Acids and Bases, Elsevier Science Publishers B.V.; Imelik, B., Naccache, C., Coudurier, G., Ben Taarit, Y., Vedrine, J. C. Eds.; 1985,419426.

(16) Samad, J. E.; Blanchard, J.; Sayag, C.; Louis, C.; J.R. Regalbuto. The controlled synthesis of metal-acid bifunctional catalysts. J. Catal. 2016, 342,203-212.

(17) Weisz, P. B. Polyfunctional Heterogeneous Catalysis. Adv. Catal. 1962, 13,137-190. 
(18) Zečević; J.; Vanbutsele, G.; P. de Jong, K.; Martens, J. A. Nanoscale intimacy in bifunctional catalysts for selective conversion of hydrocarbons. Nature 2015, 528,245-254.

(19) Chareonpanich, M.; Zhang, Z.-G.; Tomita, A. Hydrocracking of Aromatic Hydrocarbons over USY-Zeolite. Energy Fuels 1996, 10,927-931.

(20) Guillon, E.; Lacombe, S.; Sozinho, T.; Magnoux, P.; Gnep, S.; Moreau, P.; and Guisnet, M. How to Improve the Selectivity of Zeolitic Catalysts in C8 Aromatic Cut Isomerization. Oil Gas Sci. Technol.- Rev. IFP 2009, 64,731-744.

(21) Moreau, F.; Moreau, P.; Gnep. N.S.; Magnoux. P.; Lacombe. S.; Guisnet, M. Ethylbenzene isomerization over bifunctional platinum alumina-EUO catalysts: Location of the active sites. Microporous Mesoporous Mater. 2006, 90,327-338.

(22) Ertl, G.; Knözinger, H.; Weitkamp, J. in Preparation of solid acids, Wiley-VCH, Germany 1999.

(23) Alvarez, F.; Ribeiro, F. R.; Perot, G.; Thomazeau, C.; Guisnet, M. Hydroisomerization and Hydrocracking of Alkanes. J. Catal. 1996, 162,179-189.

(24) Guisnet, M. “Ideal” bifunctional catalysis over Pt-acid zeolites. Catal. Today 2013, 218$219,123-134$.

(25) Batalha, N.; Pinard, L.; Pouilloux, Y.; Guisnet, M. Bifunctional Hydrogenating/Acid Catalysis: Quantification of the Intimacy Criterion. Catal. Lett. 2013, 143,587-591.

(26) Batalha, N.; Pinard, L.; Bouchy, C.; Guillon, E.; Guisnet, M. n-Hexadecane hydroisomerization over Pt-HBEA catalysts. Quantification and effect of the intimacy between metal and protonic sites. J. Catal. 2013, 307,122-131. 
(27) Alvarez, F.; Giannetto, G.; Guisnet, M.; Perot, G. Hydroisomerization and hydrocracking of n-Alkanes. 2. n-Heptane transformation on a Pt-dealuminated Y zeolite - comparison with a Pt-Y zeolite. Appl. Catal. 1987, 34,353-365.

(28) Galarneau, A.; Villemot, F.; Rodriguez, J.; Fajula, F.; Coasne, B. Validity of the t-plot method to assess microporosity in hierarchical micro/mesoporous materials. Langmuir 2014, $30,13266-13274$.

(29) Fadoni, M.; Lucarelli, L. Temperature programmed desorption, reduction, oxidation and flow chemisorption for the characterisation of heterogeneous catalysts. Theoretical aspects, instrumentation and applications. Stud. Surf. Sci. Catal. 1998, 120,177-225.

(30) Mendes, P. S. F. Silva, J. M. Ribeiro, M. F. Duchêne, P. Daudin, A. Bouchy, C. Quantification of metal-acid balance in hydroisomerization catalysts. AlChE J. 2017, 63,28642875.

(31) Hadjiivanov, K. I.; Vayssilov, G. N. Characterization of oxide surfaces and zeolites by carbon monoxide as an IR probe molecule. Adv. Catal. 2002, 47,307-511.

(32) Antos, G. J.; Aitani, A. M. in Catalytic naphtha reforming, 2nd ed.; Chemical industries 100, Marcel Dekker; London: Taylor \& Francis: New York 2004.

(33) Weitkamp, J.; Ernst. S.; Karge. H. G. Peculiarities in the Conversion of Napthenes on Bifunctional Catalysts. Erdöl, Kohle-Erdgas -Petrochem 1984,457-462.

(34) Ribeiro, F.; Marcilly, C.; Guisnet, M. Hydroisomerization of n-hexane on platinum zeolites I. Kinetic study of the reaction on platinum/Y-zeolite catalysts. J. Catal. 1982, 78,267274. 
(35) Chevalier F., Guisnet M., Maurel R. in Tracer study of the isomerization of paraffins on bifunctional catalysts, Proceedings of the Sixth International Congress on Catalysis 1, 478-487.

(36) Weitkamp, J. Catalytic Hydrocracking-Mechanisms and Versatility of the Process. ChemCatChem 2012, 4,292-306.

(37) Weitkamp, J.; Jacobs, P. A.; Ernst. S. Shape Selective Isomerization and Hydrocracking of Naphthenes Over Pt/HZSM-5 Zeolite. in Structure and Reactivity of Modified Zeolites, Elsevier Science Publishers B.V.; Jacobs, P. A. Ed.; 1984.

(38) Csicsery, S. M. Shape-selective catalysis. Zeolites 1984, 4,202-213. 

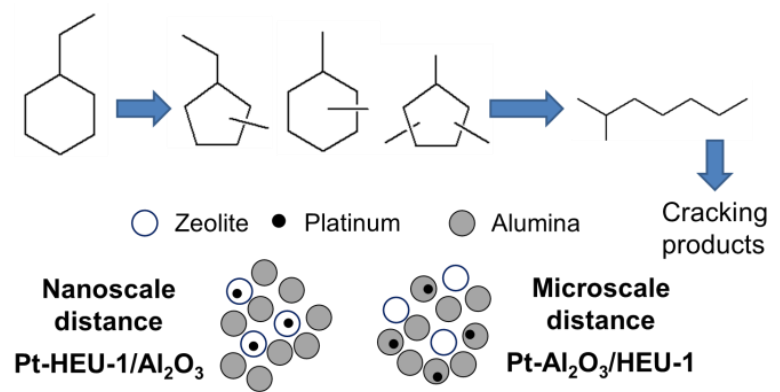